\title{
Estado da arte da indústria gaúcha referente ao uso de técnicas de inteligência artificial por meio de um survey
}

\author{
Ivan Luis Suptitz ${ }^{1}$, Rejane Frozza ${ }^{1}$, Rolf Fredi Molz ${ }^{1}$ \\ ${ }^{1}$ Universidade de Santa Cruz do Sul (UNISC) \\ Avenida Independência - 2293 - 96.815-900 - Santa Cruz do Sul - RS - Brasil \\ ivansuptitz@gmail.com, \{frozza, rolf\}@unisc.br
}

\begin{abstract}
This research intends identify the state of the art of the application of some techniques of Artificial Intelligence (AI) in the Brazilian industry of Rio Grande do Sul using survey methodology. The focus of the survey is on the techniques of Artificial Neural Networks and Fuzzy Logic, but also Data Mining and Knowledge Based Systems were evaluated. The results show that most companies have little contact with these techniques, and that the biggest reason for the low utilization is the lack of knowledge about the technology and possible applications. Important aspects were also defined for the development of a tool that applies AI techniques focused on the industry.
\end{abstract}

Resumo. Este trabalho busca identificar o estado da arte da aplicação de algumas técnicas de Inteligência Artificial (IA) na indústria brasileira gaúcha por meio de um levantamento do tipo survey. O foco do levantamento está nas técnicas de Redes Neurais Artificiais e Lógica Fuzzy, mas também foram avaliadas Mineração de Dados e Sistemas Baseados em Conhecimento. Os resultados demonstram que a maioria das empresas tem pouco contato com estas técnicas, e que o maior motivo da baixa utilização é o desconhecimento da tecnologia e das aplicações possíveis. Também foram levantados aspectos importantes para o desenvolvimento de uma ferramenta que aplique técnicas de IA com foco na indústria.

\section{Introdução}

Técnicas de inteligência artificial (IA) como redes neurais artificiais (RNAs) e sistemas fuzzy podem ser utilizadas na indústria em diversas aplicações [Valle e Sussner 2011], [Ros e Pasero 2013], [Taghadomi-Saberi et al. 2014], [Geetha 2015]. As RNAs têm um espaço interessante devido a sua capacidade de criar modelos baseados em conhecimentos implícitos e sua capacidade de generalização [Lima, Pinheiro e Santos 2014]. Sistemas de lógica fuzzy, por sua vez, facilitam o trabalho de modelagem do conhecimento explícito de um especialista humano constituindo uma ferramenta conveniente para manipulação de valores imprecisos ou vagos, que são muito comuns no comportamento humano [Lin e Lee 1995].

A técnica de RNAs têm sua arquitetura inspirada no modo como trabalha o cérebro humano, com o objetivo de tentar reproduzir suas habilidades como o reconhecimento de padrões [Haykin 1999]. Em [Suptitz, Frozza e Molz 2015] é possível encontrar uma lista de ferramentas que possibilitam modelagem e testes com RNAs.

A lógica fuzzy, pode ser compreendida como uma extensão da lógica booleana, possibilitando operações com variáveis cujos valores não são absolutos, mas apresentam um certo grau de pertinência aos conjuntos definidos. Um típico sistema baseado em lógica difusa é composto de uma etapa de fuzzificação, uma máquina de inferência e uma etapa de defuzzificação [Mamdani 1973]. 
Existem outras técnicas de IA aplicáveis na indústria. Este artigo apresenta um enfoque especial sobre as RNAs e sistemas fuzzy por uma questão de limitação de escopo e para servir de base a um segundo trabalho no qual se propõe uma ferramenta que possibilita a modelagem de sistemas neuro-fuzzy que combinam as duas técnicas citadas.

De acordo com Bravo et al. (2014) a Inteligência Artificial, vem sendo utilizada há pelo menos duas décadas na indústria americana, mas ainda não pode ser considerada uma tecnologia consolidada. Apesar de constatar que cerca de 50\% dos entrevistados tinham algum contato com IA, os autores também observaram que o conhecimento público desta tecnologia é baixo [Bravo et al. 2014].

Apesar da constatação anterior e da existência de farta literatura sobre aplicações de IA em ambiente industrial, não se conhece o nível de envolvimento da indústria brasileira com esta tecnologia. Inicialmente, foi realizada uma avaliação bibliométrica no portal de periódicos CAPES, a fim de encontrar pesquisas que tratassem da aplicação de técnicas de IA na indústria brasileira.

Esta avaliação foi realizada no dia 14 de novembro de 2015. Não foram aplicados filtros de data, tipo de material ou idioma. Foram realizadas as 8 combinações de palavraschaves conforme apresentado no Quadro 1.

\section{Quadro 1 - Levantamento bibliométrico de surveys em IA}

\begin{tabular}{|c|l|c|}
\hline $\mathbf{N}^{\mathbf{l}}$ & Combinação de palavras & Resultados \\
\hline 1 & "artificial intelligence" AND "industry" AND "survey" & 120 \\
\hline 2 & "neural networks" AND "industry" AND "survey" & 83 \\
\hline 3 & $\begin{array}{l}\text { "artificial intelligence" AND "industry" AND "survey" AND ("Brasil" OR "Brazil" OR } \\
\text { "brasileiras" OR "Rio Grande do Sul" OR "gaúcha" OR "gaúchas") }\end{array}$ & 0 \\
\hline 4 & $\begin{array}{l}\text { "neural networks" AND "industry" AND "survey" AND ("Brasil" OR "Brazil" OR } \\
\text { "brasileiras" OR "Rio Grande do Sul" OR "gaúcha" OR "gaúchas") }\end{array}$ \\
\hline 5 & "inteligência artificial" AND "indústria" AND "survey" & 0 \\
\hline 6 & "redes neurais" AND "indústria" AND "survey" & 0 \\
\hline 7 & "inteligência artificial" AND "indústria" AND "pesquisa" & 0 \\
\hline 8 & "redes neurais" AND "indústria" AND "pesquisa": & 4 \\
\hline
\end{tabular}

Fonte: Elaborado pelos autores a partir de consulta no site http://periodicos.capes.gov.br acesso em: 14 nov. 2015.

Considerando que:

- As combinações 1 e 2 não filtram a questão local (Brasil ou Rio Grande do Sul). Eles retornaram respectivamente 120 e 83 resultados, demonstrando a existência de pesquisa desta natureza em nível internacional.

- Os arranjos 3 e 4 foram elaborados com a intenção de encontrar material publicado na língua inglesa, relacionado a pesquisas realizadas no Brasil ou no Rio Grande do Sul (caso houvesse sido omitida a informação do país). Ambas as buscas retornaram nenhum resultado. 
- As combinações de palavras chaves 5, 6, 7 e 8 tem como objetivo identificar material publicado em língua portuguesa que por ventura não fizesse referência ao país ou à unidade federativa. As combinações 5 e 6 não retornaram resultado e os resultados dos arranjos 7 e 8 não são levantamentos do tipo survey.

Observa-se que não foram encontrados levantamentos que tratem do panorama de técnicas de IA na indústria brasileira. Entretanto, há a necessidade de se compreender o estado da arte da aplicação de técnicas de IA em ambiente industrial, a fim de contribuir com a possibilidade de expansão do uso destas técnicas em diferentes contextos. Sendo assim, temse a justificativa da presente pesquisa do tipo survey.

O texto deste trabalho encontra-se organizado da seguinte forma: na Seção 2 é apresentada a fundamentação teórica; na Seção 3 está descrita a metodologia empregada; a Seção 4 apresenta os resultados e discussões do survey; e a Seção 5 finaliza o texto com as conclusões.

\section{Fundamentação Teórica}

O levantamento do tipo survey (também chamado de pesquisa de avaliação) propõe-se a realizar a coleta de dados e informações sobre os indivíduos e o seu ambiente em uma área particular de interesse, de forma que permita obter um panorama sobre determinado fenômeno, ou extrair conclusões do tipo causa e efeito entre as variáveis [Miguel e Lee Ho 2009].

Este tipo de pesquisa pode ser utilizado para avaliar a utilização, por parte da indústria, de técnicas amplamente conhecidas no meio acadêmico. Um exemplo disso ocorre no trabalho de Giacon e Mesquita (2011) no qual os autores avaliaram a aplicação prática das técnicas de programação detalhada da produção junto à indústria paulista, por meio de um survey.

Na Figura 1 estão descritas as etapas de um levantamento do tipo survey.

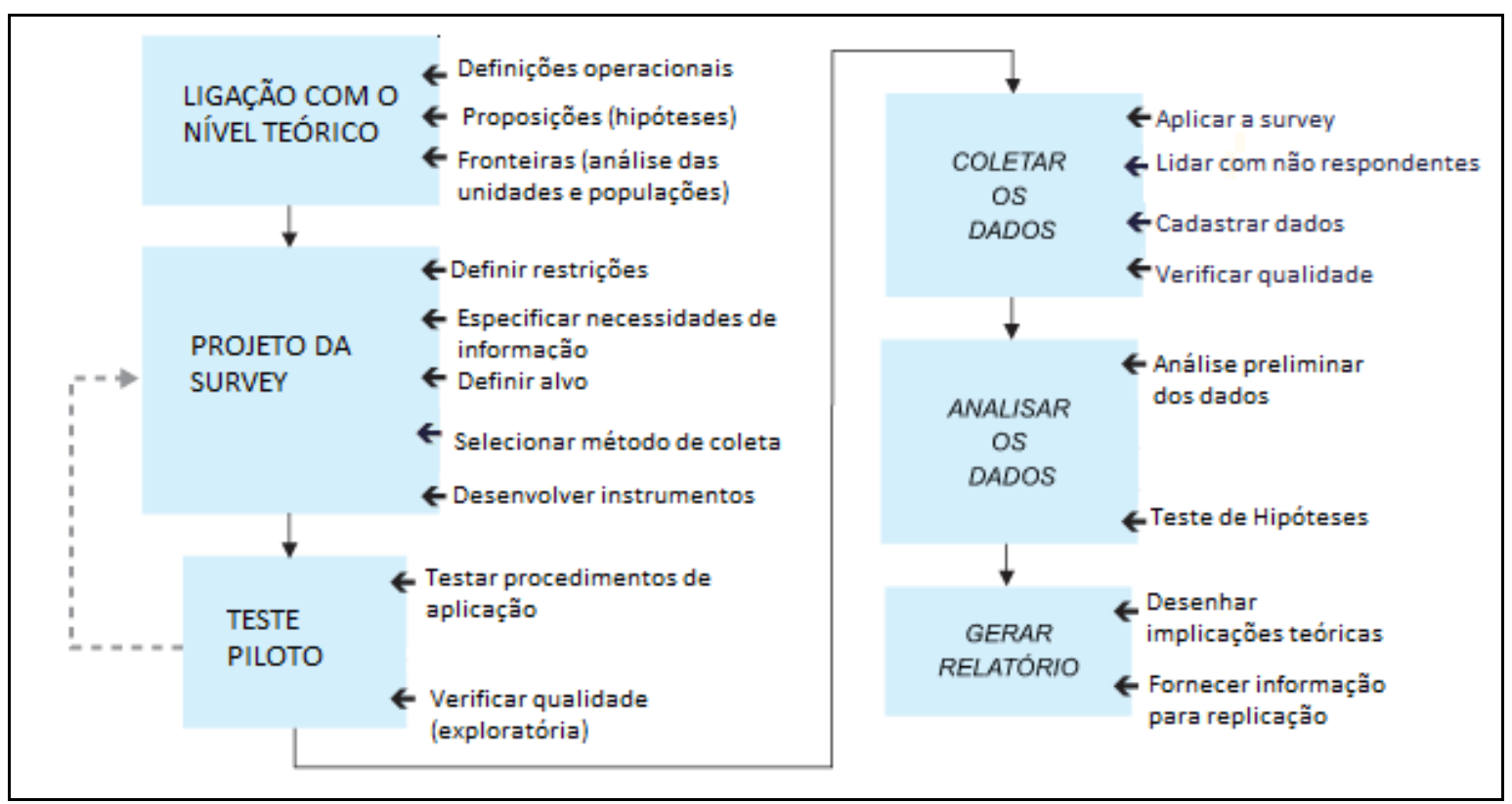

Figura 1. Etapas de um levantamento tipo survey. Fonte: Forza (2002). 
A primeira etapa do survey consiste em reunir o aporte teórico necessário para definir as hipóteses e as populações que possivelmente serão alvo da pesquisa. Depois disso, na segunda etapa, inicia-se o projeto do survey propriamente dito quando são definidos os métodos e instrumentos da coleta, inclusive o questionário. A terceira etapa consiste na realização de um teste piloto com indivíduos do mesmo perfil dos que devem responder o questionário. Em seguida, ocorrem as etapas de coleta dos dados junto à população e a análise desses dados. Na etapa final, é gerado um relatório que lista os resultados da pesquisa [Forza 2002].

Para definir o público alvo da pesquisa, é preciso conhecer a organização do setor industrial brasileiro. As indústrias estão classificadas por atividade econômica de acordo com a Classificação Nacional de Atividade Econômica (CNAE). Esta classificação é estruturada de forma hierárquica com 21 seções, 87 divisões, 285 grupos, 673 classes e 1301 subclasses. A hierarquia parte de uma visão abrangente da economia (seções) em direção a divisões cada vez mais específicas [IBGE 2007].

Um exemplo desta estrutura é a classificação: 1011201. Os primeiros 2 dígitos se referem à divisão (no caso é 10: Fabricação de produtos alimentícios). As divisões de 10 a 33 compreendem a seção $\mathrm{C}$ (Indústrias de Transformação). $\mathrm{O}$ terceiro dígito ajuda a compor o grupo (no caso 10.1: Abate e fabricação de produtos de carne). A classe é determinada pela concatenação dos 3 dígitos do grupo com um dígito que caracteriza a classe e um dígito verificador (no caso 10.11-2: Abate de reses, exceto suínos). Por fim, ocorre a identificação da subclasse (no caso 10.11-2/01: Frigorífico - abate de bovinos) [IBGE 2007].

\section{Metodologia da pesquisa}

Para atender ao objetivo do trabalho, identificou-se 3 grandes questões que precisam ser respondidas no levantamento. Juntamente com cada questão (Q), foi construída uma hipótese (H) para ser validada:

- Q1: Qual o nível de contato que as indústrias gaúchas têm com técnicas de IA, em especial com RNA e lógica fuzzy?

- H1. A maioria das empresas tem pouco, ou nenhum contato com estas técnicas de inteligência artificial.

- Q2: Quais são os empecilhos para a utilização de IA nas indústrias gaúchas?

○ H2. Desconhecimento das aplicações possíveis e dos benefícios que podem ser obtidos leva as indústrias a não investir neste tipo de tecnologia.

- Q3: Quais são os requisitos que uma ferramenta de modelagem de RNAs e lógica fuzzy deve ter para ser aplicada na indústria?

- Sem hipótese (questão exploratória).

As questões de pesquisa foram transformadas em um questionário de 12 questões distribuído da seguinte forma:

- 6 questões referentes à Q1.

- 1 questão referente à Q2.

- 2 questões referentes à Q3.

- 3 perguntas para caracterizar a empresa e o respondente. 
As questões referentes à Q1 possuem um viés didático, explicando rapidamente os conceitos antes de efetivamente fazer a pergunta. O objetivo disso é fornecer um amparo aos respondentes que por ventura não tenham tido contato com conceitos da área de inteligência artificial, evitando uma resposta inconsciente. Procurou-se também utilizar uma linguagem de fácil acesso, sempre procurando relacionar o tema com possíveis cenários na indústria, com os quais o respondente tenha mais familiaridade.

A fronteira inicialmente definida foi todo o setor industrial brasileiro. Este escopo foi reduzido para indústrias do Rio Grande do Sul devido a limitações de tempo, orçamento e dificuldade de obtenção das listas de contatos junto às Federações de Indústria de alguns estados.

A lista de indústrias gaúchas e seus respectivos contatos foram obtidos mediante a aquisição do Cadastro Industrial do Rio Grande do Sul junto à Federação das Indústrias do estado do Rio Grande do Sul [FIERGS 2015].

De posse do cadastro, foi possível realizar uma análise dos dados disponíveis visando definir o alvo da pesquisa. Na Figura 2 visualiza-se a representação da proporção de indústrias por seção de atividade.

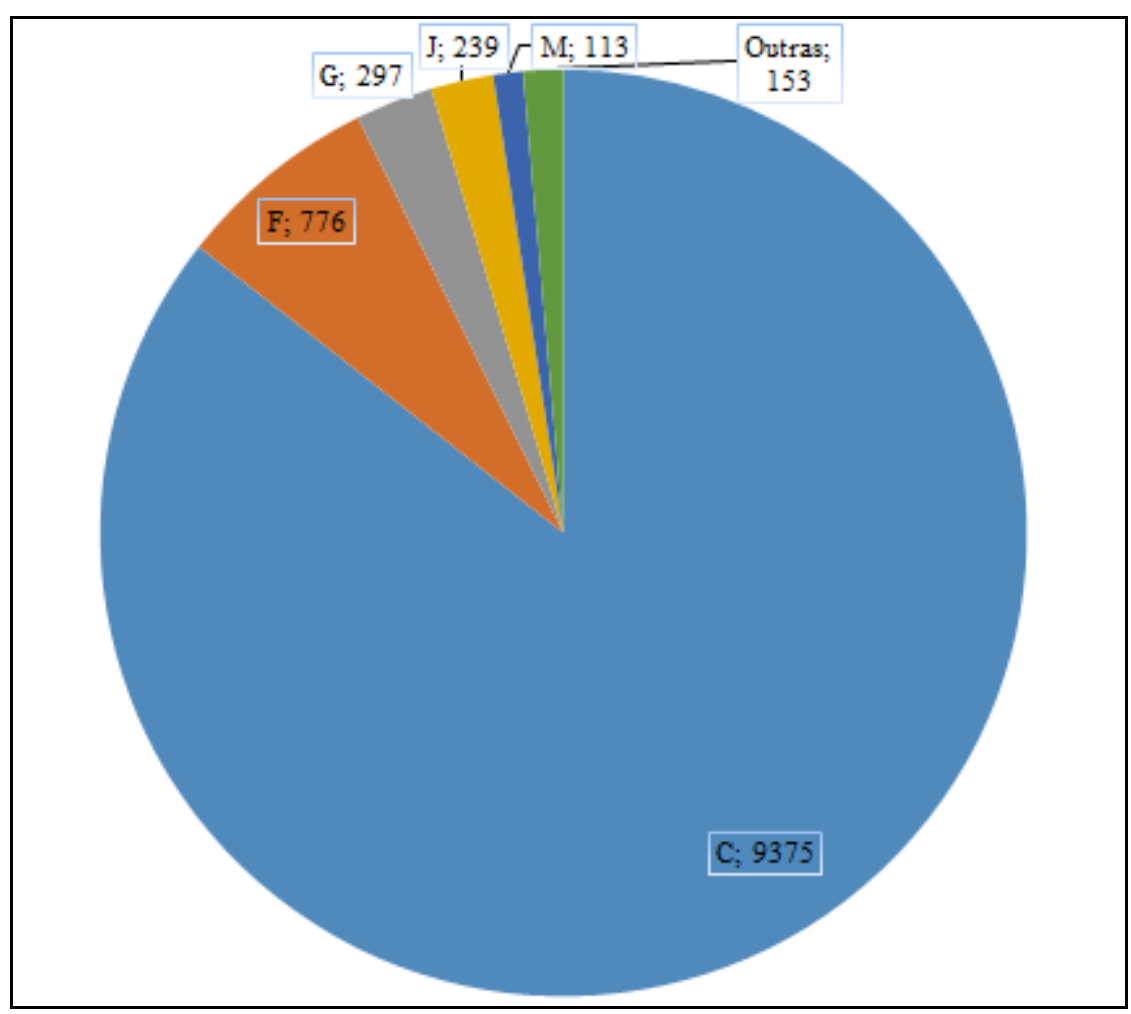

Figura 2. Indústrias gaúchas por seção de atividade. Fonte: extraído de FIERGS (2015).

O gráfico mostra que a seção C (Indústrias de transformação) representa $86 \%$ das indústrias do RS; a seção F (Construção) representa 7\%; a seção G (Comércio - reparação de veículos automotores e motocicletas) representa 3\%; a seção J (Informação e comunicação) representa 2\%; a seção $\mathrm{M}$ (Atividades profissionais, científicas e técnicas) representa 1\%; e todas as demais seções também $1 \%$.

Em virtude da alta representatividade da seção $C$, optou-se por aplicar a pesquisa nesta população específica. O número de indústrias na seção C é 9.375 . Destas, 6.889 possuem $e$ - 
mail vinculado, mas 151 endereços eletrônicos são repetidos (uma hipótese é que as empresas seriam do mesmo proprietário), restando uma população a ser pesquisada de 6.738 indivíduos.

Uma vez definidos o questionário e a população a ser pesquisada, passou-se às etapas seguintes do projeto: a forma de coleta escolhida foi um formulário on-line cujo link de acesso foi enviado por e-mail aos respondentes.

O teste piloto foi realizado com 2 indústrias da seção $C$ (uma indústria de equipamentos eletrônicos e um frigorífico de suínos). As sugestões destes respondentes foram no sentido de dispor mais opções de questões abertas e opções para que leigos que desconhecem totalmente o assunto também pudessem responder.

Feitas as correções, iniciou-se a coleta de dados com o envio dos e-mails para a lista de contatos. $\mathrm{O}$ envio dos e-mails foi realizado com auxílio de um software desenvolvido pelo autor com este fim específico. Devido a limitações do servidor do correio eletrônico, somente podem ser enviadas mensagens com até 100 destinatários por vez, num total diário de no máximo 1000. Em cada e-mail, dos 100 destinatários, 99 são contatos da lista da FIERGS e 1 deles é o endereço do próprio autor para confirmar que o envio ocorreu com sucesso. Os destinatários das mensagens foram informados no campo de cópia oculta (BCC) para não disseminar publicamente os contatos dos respondentes.

A cada duas semanas, realizou-se o reenvio de um e-mail para lembrar da pesquisa, reforçar o pedido de resposta e reafirmar questões de segurança quanto aos dados do respondente, segurança do link e ainda a opção de remoção da lista de contatos caso o destinatário se sentisse incomodado com as mensagens.

A cada iteração foi adotado o seguinte procedimento:

1. Verificar as respostas do questionário e remover da lista os contatos que responderam.

2. Verificar os e-mails retornados com erro e remover da lista (pois são inacessíveis).

3. Verificar as solicitações de exclusão e remover estes contatos da lista.

4. Reenviar a mensagem alterando levemente o texto do título e do corpo visando reduzir o risco de ela ser classificada como Spam.

O questionário permaneceu on-line do dia 14 de novembro de 2015 ao dia 16 de agosto de 2016. No total foram realizadas 10 iterações de envio de e-mail, cada uma com cerca de 56 e-mails e cada e-mail com 99 destinatários, totalizando 55.440 mensagens.

\section{Resultados e discussão}

Durante a pesquisa verificou-se o retorno por falha de 1.133 e-mails. Os motivos das rejeições foram, em sua maioria, a inexistência da caixa de e-mail ou do servidor. Isso pode ocorrer devido à empresa ter trocado ou desativado o seu endereço eletrônico ou ainda que tenha cadastrado incorretamente seu contato junto à FIERGS. De qualquer forma, estes contatos são inatingíveis pela pesquisa proposta, restando assim uma população mensurável de 5.605 indivíduos.

Além disso, 37 pessoas retornaram o e-mail informando que não gostariam de participar. Estas pessoas foram removidas da lista de contatos para que não recebessem mais mensagens. Mesmo assim, elas permanecem somadas no total da população mensurável.

Ao final do processo do survey, obteve-se 102 respostas. Para avaliar a qualidade estatística desta amostra, utilizou-se a equação para determinação do tamanho de amostras 
para populações finitas, pois o tamanho da população é conhecido. Esta equação relaciona nível de confiança, margem de erro, número de amostras e heterogeneidade das mesmas [Triola 1999].

Como o número de amostras é fixo, sendo determinado pela quantidade de respostas obtidas, resta determinar os demais parâmetros: A heterogeneidade é usualmente fixada em $50 \%$ atendendo ao pior caso de diversidade do universo [NetQuest 2016]. Os valores típicos para nível de confiança são $90 \%, 95 \%$ e $99 \%$ [Triola 1999]. Para este trabalho, foi adotado o nível de $90 \%$ por questão de simetria com a margem de erro. Aumentar a confiança, implica aumento da margem de erro.

O cálculo foi realizado no site NetQuest (2016). Adotando um fator de confiança de $90 \%$, com uma homogeneidade de $50 \%$, obtém-se uma margem de erro de $\pm 8,1 \%$. Isso significa que $90 \%$ das vezes, o dado real estará na faixa de $\pm 8,1 \%$ a respeito dos dados da pesquisa relatados a seguir.

Verifica-se que $86,3 \%$ dos respondentes afirmam desconhecer as técnicas de RNA ou não sabem como aplicá-las na empresa. Estes números são demonstrados na Figura 3 ao somar as respostas "Nunca ouvi falar" $(61,8 \%)$ e "Ouvi falar, mas não sei como aplicar na empresa" $(24,5 \%)$.

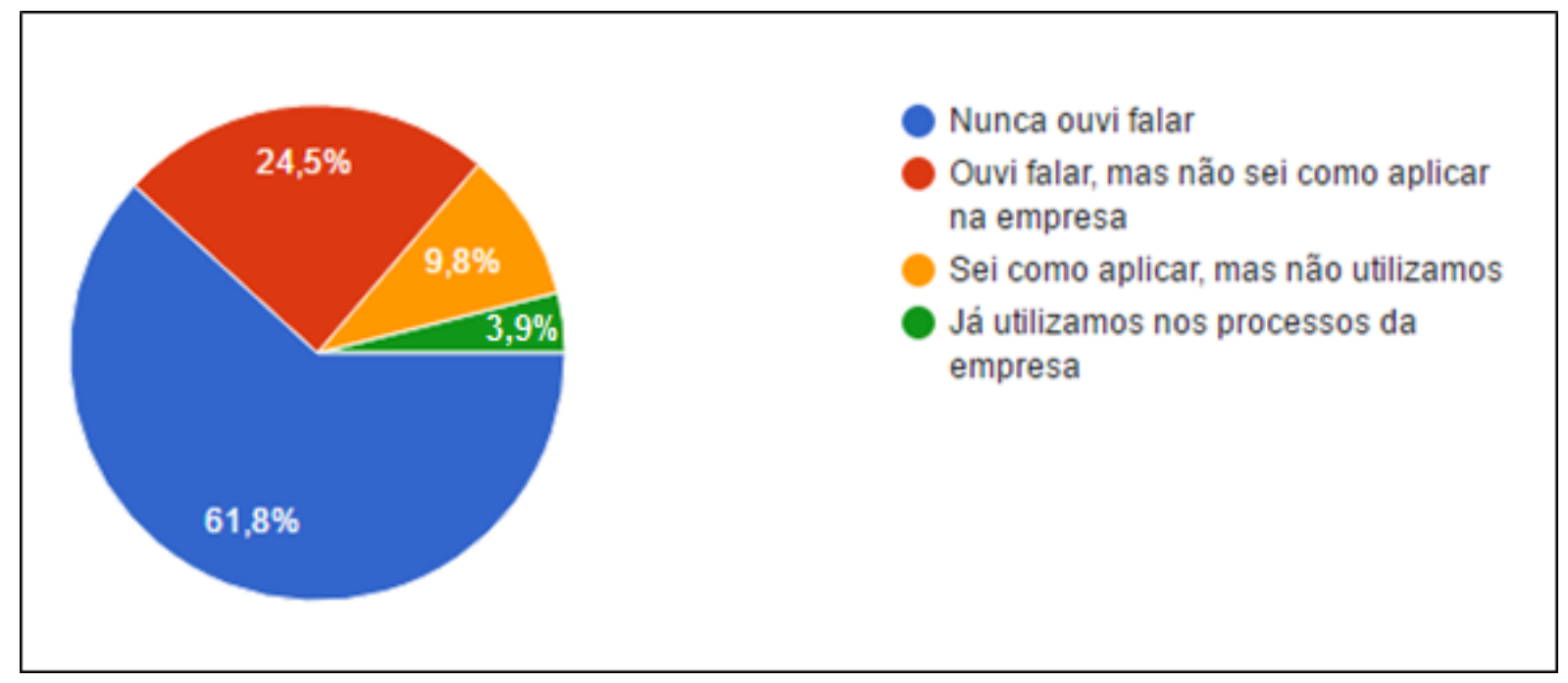

Figura 3. Conhecimento da indústria sobre RNA 
De forma análoga, 86,3\% dos respondentes desconhecem a lógica fuzzy ou não sabem como aplicá-la na empresa. Estes valores são demonstrados na Figura 4 novamente ao somar as opções "Nunca ouvi falar" (70,6\%) e "Ouvi falar, mas não sei como aplicar na empresa" $(15,7 \%)$.

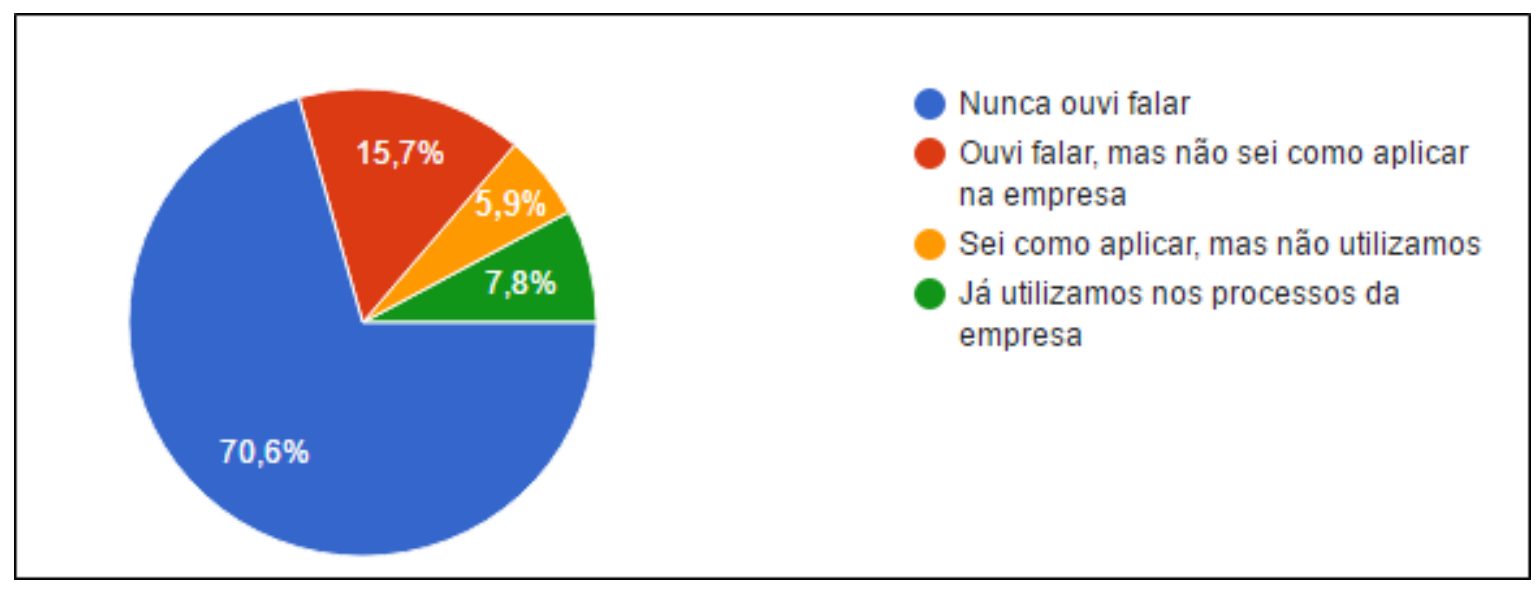

Figura 4. Conhecimento da indústria sobre lógica fuzzy

Questionados sobre o envolvimento com a técnica de mineração de dados, 76,5\% dos respondentes afirmam que não conhecem ou não sabem como aplicar na sua empresa. Esta informação é obtida a partir da leitura da Figura 5.

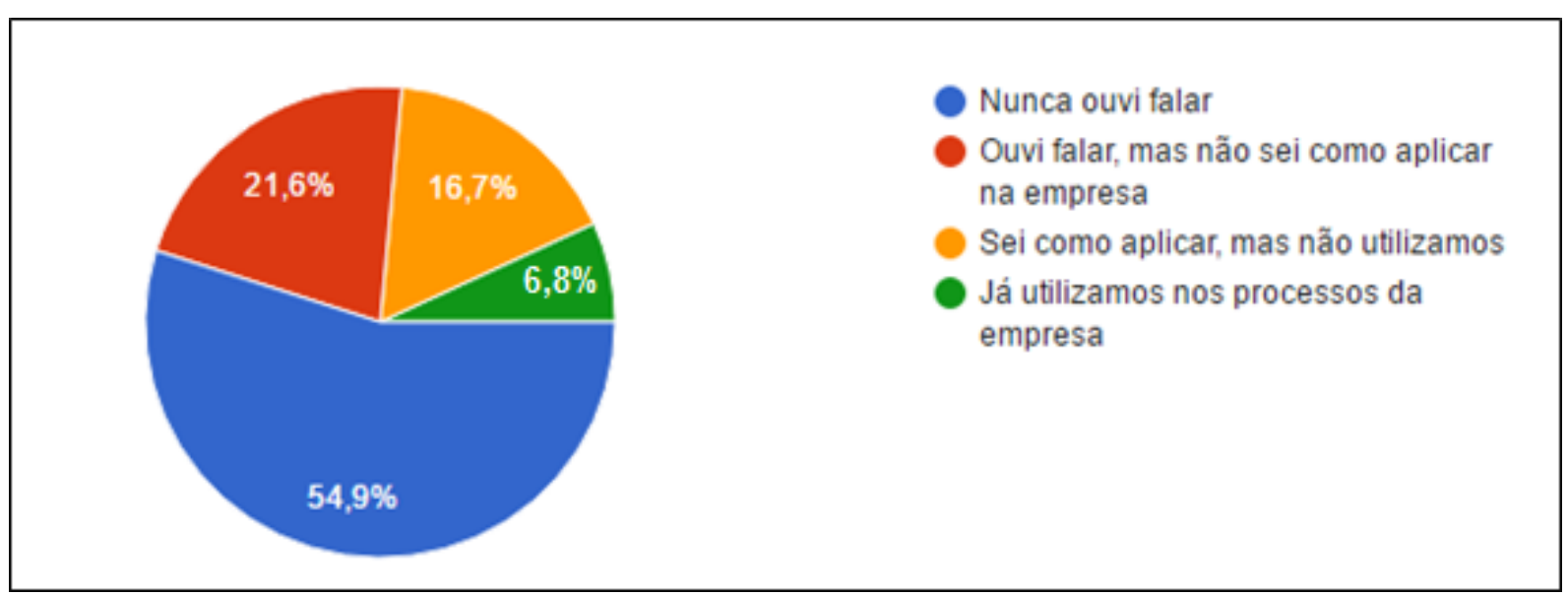

Figura 5. Envolvimento da indústria com mineração de dados

Já na Figura 6 pode-se observar a distribuição das respostas referentes ao envolvimento da indústria com sistemas baseados em conhecimento. Pela primeira vez, constata-se uma utilização mais significativa da técnica, apesar de ainda minoritária, alcançando $19,6 \%$. 


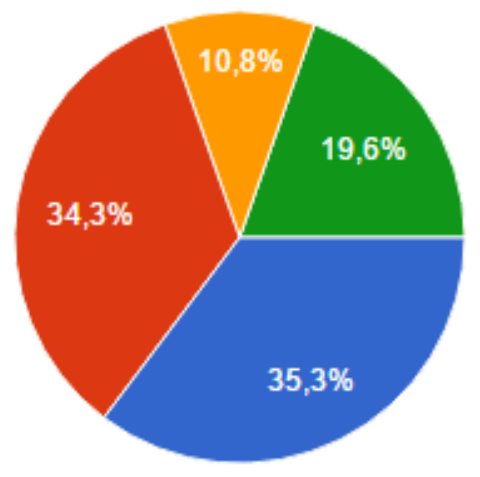

Nunca ouvi falar

Ouvi falar, mas não sei como aplicar na empresa

Sei como aplicar, mas não utilizamos

Já utilizamos nos processos da empresa

Figura 6. Envolvimento da indústria com sistemas baseados em conhecimento

Questionados sobre o motivo da pouca aplicação de técnicas de IA no meio industrial, os fatores mais citados pelos respondentes foram desconhecimento e alto custo. Esta interpretação pode ser obtida a partir da Figura 7, na qual se observa que 33,3\% assinalam o fator desconhecimento da tecnologia, $21,6 \%$ citam o desconhecimento dos benefícios que podem ser trazidos com as técnicas e $23,5 \%$ citam o alto custo que imaginam que ferramentas desta natureza devam ter.

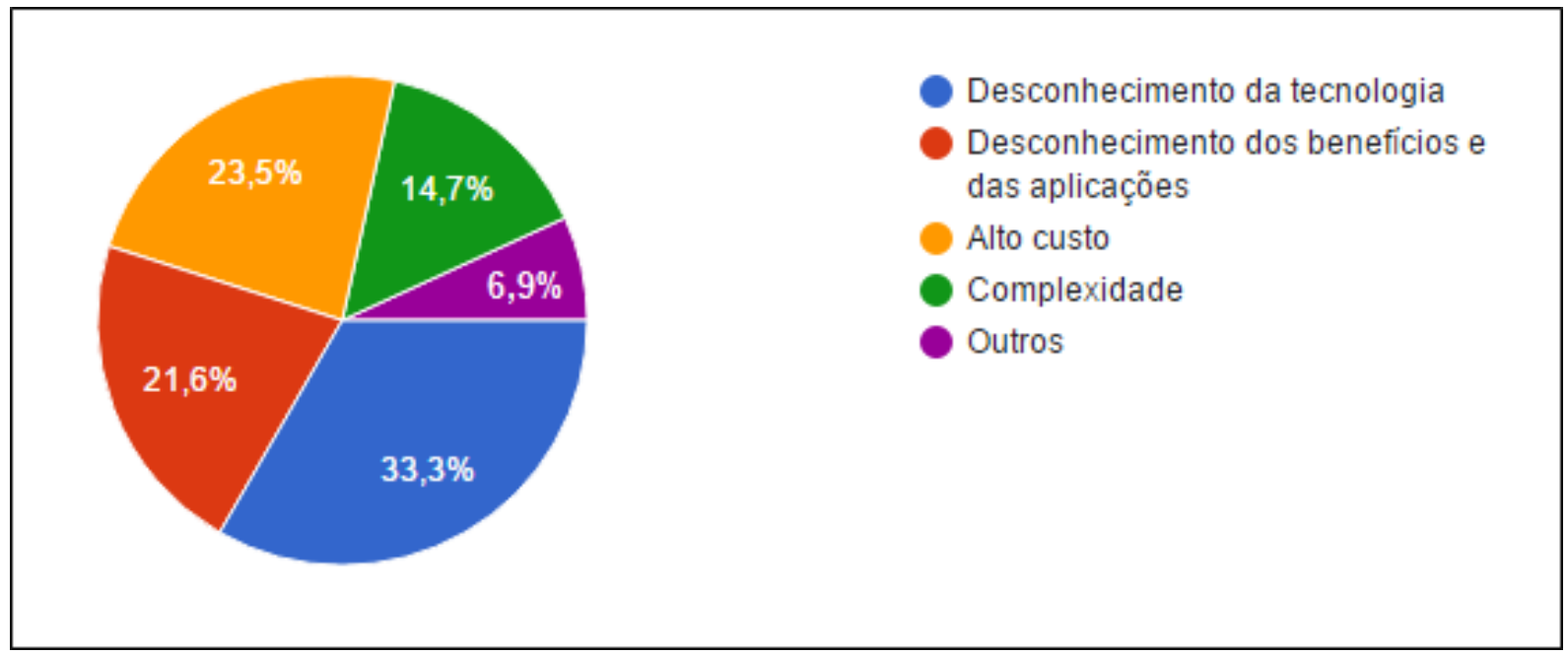

Figura 7. Motivos para não aplicar IA na indústria 
Na Figura 8, pode-se observar as respostas de uma questão exploratória que visou descobrir quais os pontos esperados de uma ferramenta de IA para a indústria. Na opinião dos respondentes, baixo custo e facilidade de uso são os requisitos mais importantes de uma ferramenta que se proponha a combinar RNA e lógica fuzzy para fins industriais.

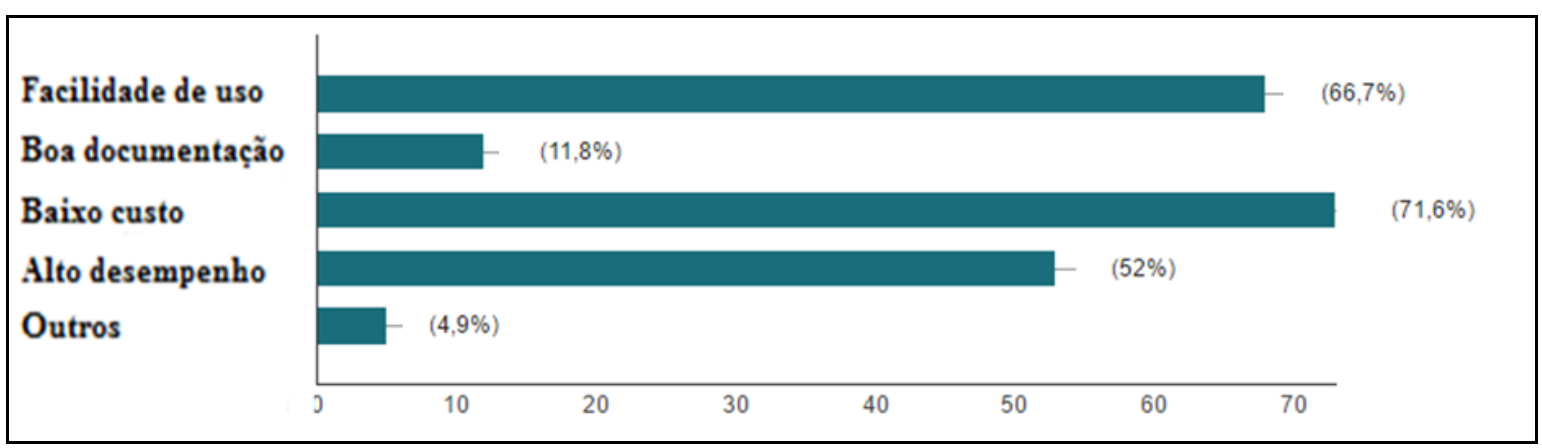

Figura 8. Requisitos esperados de uma ferramenta de RNA

Em outra questão exploratória, os respondentes foram estimulados a assinalar tarefas que são tipicamente resolvidas com aplicação de técnicas de inteligência artificial e que seriam mais úteis em sua empresa. As respostas estão exibidas na Figura 9. Como se pode observar, os itens mais lembrados são: descobrir informações ocultas no processo e predizer comportamentos do processo de produção, ambas marcadas por $52 \%$ dos pesquisados.

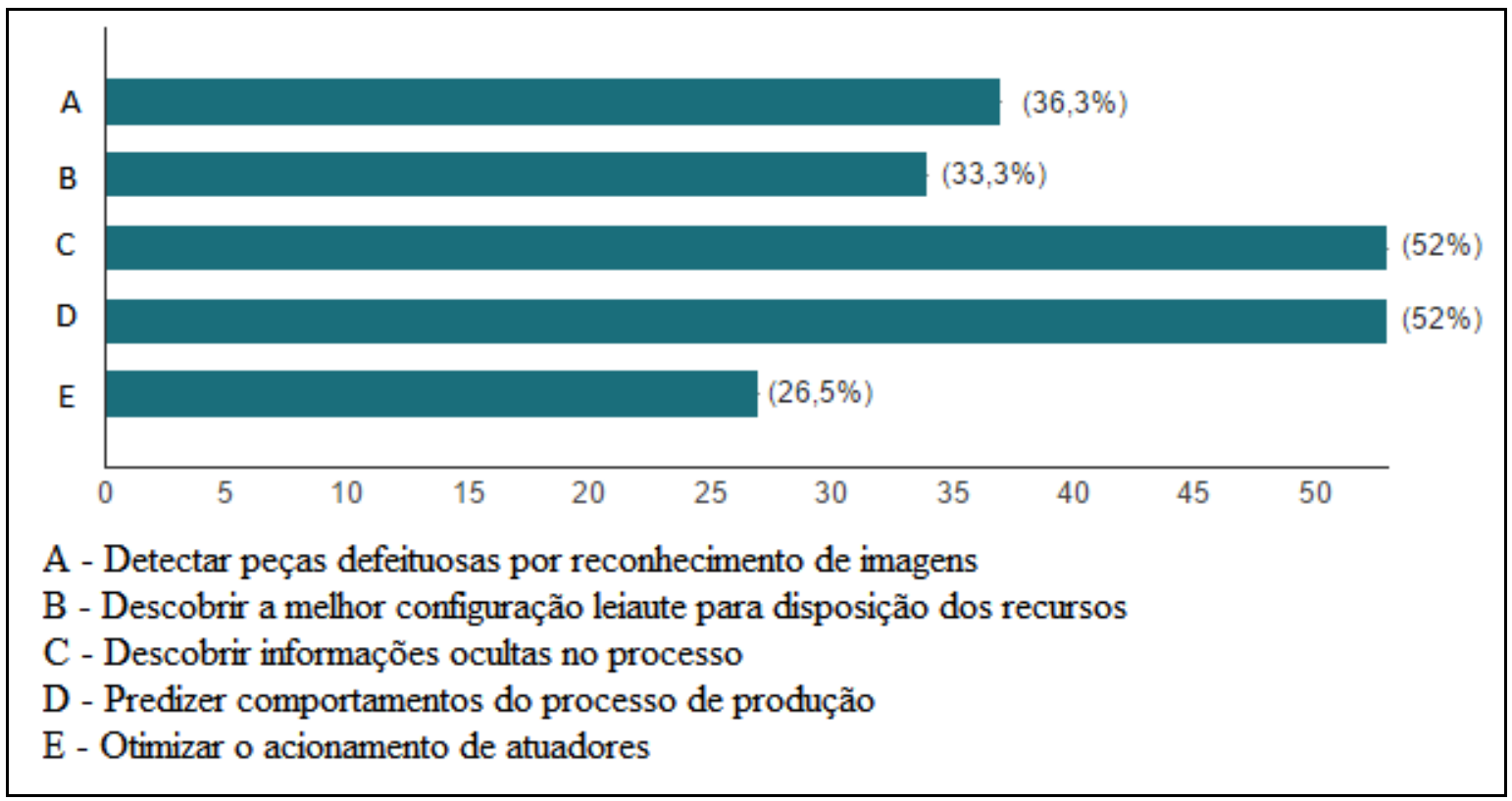

Figura 9. Tarefas mais úteis na indústria

Com o resultado da questão exploratória exibido na Figura 10 que buscou junto aos respondentes quais são as técnicas de IA mais conhecidas, verifica-se que a técnica mais lembrada é a de Sistemas Baseados em Conhecimento com $62 \%$ das respostas. Lógica fuzzy e RNA são as técnicas menos conhecidas com $11,4 \%$ e $24,1 \%$ respectivamente. 


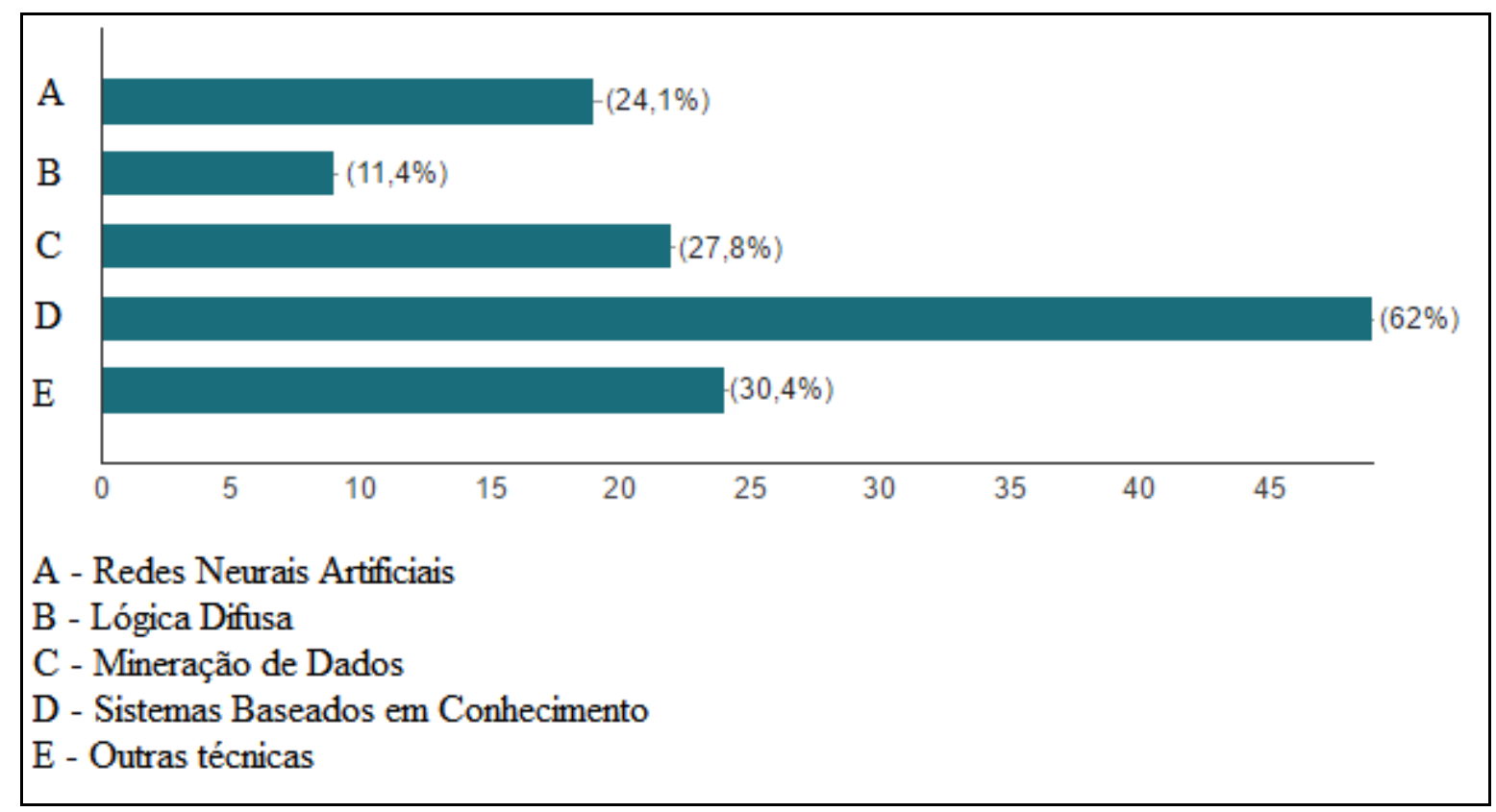

Figura 10. Técnicas de IA conhecidas

Com estes dados foi possível obter o panorama desejado da aplicação de IA na indústria gaúcha. Verifica-se que o conhecimento e utilização são mais baixos para as técnicas de redes neurais artificiais e lógica fuzzy. Apesar disso, predição de comportamentos do processo de produção é considerada uma das tarefas mais úteis, a qual está intimamente ligada a RNAs.

Ao mesmo tempo, foi possível verificar que os requisitos mais importantes em uma ferramenta que se proponha a oferecer estas tecnologias são o baixo custo e a facilidade de uso. Este dado sinaliza que a indústria aceitaria mais facilmente uma ferramenta de uso gratuito desenvolvida com atenção especial para questões de ergonomia e usabilidade de software.

\section{Conclusão}

Conforme citado inicialmente, técnicas de IA como RNAs e sistemas fuzzy têm potencial de serem aplicadas na indústria, embora se acredite que sua utilização seja baixa na indústria brasileira. Com este trabalho, foi possível obter um panorama deste cenário, conforme as conclusões relatadas a seguir.

Pode-se concluir, inicialmente, que os dados do levantamento tipo survey indicam um resultado que corrobora com a hipótese H1 (a maioria das empresas tem pouco, ou nenhum contato com técnicas de inteligência artificial). Este resultado está em sintonia com a constatação de Bravo et al. (2014) de que o conhecimento público destas tecnologias é baixo.

Verifica-se também a confirmação da hipótese H2 (desconhecimento das aplicações possíveis e dos benefícios que podem ser obtidos leva as indústrias a não investir neste tipo de tecnologia). Ao mesmo tempo, observa-se uma preocupação do setor industrial com o alto custo que ferramentas com estas tecnologias podem ter. Existe, portanto, espaço para oferecer novas ferramentas de baixo custo ou treinamento com ferramentas de uso gratuito existentes no mercado. 
Os resultados do survey são considerados importantes, uma vez que demonstram o baixo envolvimento da indústria com técnicas de inteligência artificial. Por este motivo, esses resultados têm a capacidade de incentivar trabalhos que proporcionam novas ferramentas para melhorar o desempenho da indústria e de auxiliar na divulgação científica junto à sociedade. Neste sentido, ferramentas já foram desenvolvidas visando facilitar a modelagem e desenvolvimento de aplicações, como a Ferramenta ADReNA (para modelagem e desenvolvimento de aplicações em RNA) de [Kist e Frozza 2013] e o INFUZZY (ferramenta para desenvolvimento de aplicações em lógica fuzzy) de [Posselt, Frozza e Molz 2015]. Entretanto outros fatores podem ser considerados para ampliarem a gama de opções de modelagem de aplicações para uso nas indústrias, como o tratamento para o processamento de imagens e a integração de RNA e lógica fuzzy.

$\mathrm{Na}$ pesquisa apresentada em [Suptitz, Frozza e Molz 2015] foi realizado um levantamento de ferramentas de modelagem de RNAs no qual foram identificados softwares que podem ser aplicados para ocupar o espaço de oportunidade apontado pelo survey. No levantamento de ferramentas também foram identificadas lacunas que são preenchidas em um trabalho que objetivou o desenvolvimento de uma ferramenta para modelagem de sistemas de RNA com lógica fuzzy para classificação de imagens denominada PINFI (Processador de Imagens Neuro-Fuzzy para a Indústria) [Suptitz, Frozza e Molz 2017].

\section{Referências}

Bravo, C., Saputelli, L., Rivas, F., Pérez, A. G., Nikolaou, M., Zangl, G., Guzman, N., Mohaghegh, S. e Nunez, G. "State of the Art of Artificial Intelligence and Predictive Analytics in the E\&P Industry: A Technology Survey". Society of Petroleum Engineers, 2014.

FIERGS - Federação das Indústrias do estado do Rio Grande do Sul. Cadastro Industrial do Rio Grande do Sul - CD-ROM. Porto Alegre: Unidade de Estudos Técnicos, Sistema FIERGS, 2015.

Forza, C. "Survey research in operations management: A process-based perspective". International Journal of Operations \& Production Management, vol. 22, n. 2, p. 152-194, 2002.

Geetha, S. "Imaging based tablet inspection in drug industry". International Journal of Pharmacy and Technology, vol. 7, p. 8610-8617, 2015.

Giacon, E.; Mesquita, M. A. "Levantamento das práticas de programação detalhada da produção: um survey na indústria paulista". Gestão \& Produção, v. 18, n. 3, p. 487-498, 2011.

Haykin, S. "Neural Networks. A Comprehensive Foundation". $2^{\mathrm{a}}$ ed. Prentice Hall, New Jersey, USA, 1999.

IBGE. Classificação Nacional de Atividades Econômicas. Versão 2.0. Rio de Janeiro, 2007.

Kist, M. H. e Frozza, R.: “ADReNA - Ambiente de desenvolvimento de aplicações em redes neurais artificiais. " Trabalho de Conclusão de Curso, UNISC, 2013.

Lima, I., Pinheiro, C. A. M., Santos, F. A. O. “Inteligência Artificial”. Elsevier, 2014.

Lin, C. T. e Lee, C. S. G. "Neural Fuzzy Systems: A Neuro-Fuzzy Synergism to Inteligent Systems". Prentice Hall, New Jersey, USA, 1995.

SUPTITZ, I. L.; FROZZA, R.; MOLZ, R. F.

Estado da arte da indústria gaúcha referente ao uso de técnicas de inteligência artificial por meio de um survey

iSys | Revista Brasileira de Sistemas de Informação, Rio de Janeiro, vol. 10, No. 3, pp. 36-48, 2017 
Mamdani, E. H. "Applications of fuzzy algorithms for control of simple dynamic plant". Proc. IEEE 121, vol. 12, p. 1585-1588, 1973.

Miguel, P. A. C. e Lee Ho, L. "Levantamento Tipo Survey". In Paulo A Cauchick Miguel. (Org.). Metodologia de Pesquias em Engenharia de Produção e Gestão de Operações. 1 ${ }^{\mathrm{a}}$ ed. São Paulo, 73-128. Elsevier Editora Ltda, 2009.

Netquest: Calculadora de amostras. Disponível em http://www.netquest.com/br/painel/qualidade-calculadora-amostras.html. Acesso em: 28 dez. 2016.

Posselt, E. L., Frozza, R. e Molz, R. F. "INFUZZY: Ferramenta para desenvolvimento de aplicações de sistemas difusos". Revista Brasileira de Computação Aplicada vol. $7 \mathrm{n}^{\mathrm{o}} 1 \mathrm{p}$. 42-52, 2015.

Ros, P. M. e Pasero, E. "Defects Detection in Pistachio Nuts Using Artificial Neural Networks”. Smart Innovation, Systems and Technologies. vol. 19, p. 147-156, 2013.

Suptitz, I. L., Frozza, R. e Molz, R. F. "Análise Comparativa de Ferramentas de Redes Neurais Artificiais". ENEPEG $2015 . \quad$ Disponível em http://www.abepro.org.br/biblioteca/TN_STO_213_265_26950.pdf. Acesso em: 05 jan. 2017.

Suptitz, I. L., Frozza, R. e Molz, R. F. "Ferramenta para modelagem de sistemas de redes neurais artificiais com lógica fuzzy e processamento de imagens para a indústria". Dissertação de Mestrado, Santa Cruz do Sul, 2017.

Taghadomi-Saberi, S., Omid, M., Emam-Djomeh, Z. e Ahmadi, H. "Evaluating the potential of artificial neural network and neuro-fuzzy techniques for estimating antioxidant activity and anthocyanin content of sweet cherry during ripening by using image processing". Journal of the Science of Food and Agriculture, vol. 94, p. 95-101, 2014.

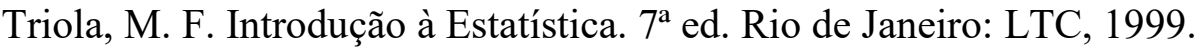

Valle, M. E. e Sussner, P. "Storage and recall capabilities of fuzzy morphological associative memories with adjunction-based learning”. Neural Networks, vol. 24, p.75-90, 2011.

SUPTITZ, I. L.; FROZZA, R.; MOLZ, R. F.

Estado da arte da indústria gaúcha referente ao uso de técnicas de inteligência artificial por meio de um survey

iSys | Revista Brasileira de Sistemas de Informação, Rio de Janeiro, vol. 10, No. 3, pp. 36-48, 2017 